\title{
Prevalence of Bullying and Cyberbullying Among Urban Middle School Students
}

\author{
George Atkins \\ Stephanie Demster \\ Kristen Dota \\ Emily Walker \\ Dr. Don Martin
}

Youngstown State University, Youngstown, OH, USA

Dr. Magy Martin

Walden University, Minneapolis, Mn, USA

Doi:10.19044/ejes.v7no2a6 URL:http://dx.doi.org/10.19044/ejes.v7no2a6

\begin{abstract}
This study examined bullying and cyberbullying among 185 middle school students in 4 urban middle schools in Ohio. Nearly $60 \%$ of the sample was female, and $67 \%$ of the sample was not Caucasian. The results indicated that bullying and cyberbullying are prevalent in this population. Approximately $44 \%$ of $6^{\text {th }}$-grade students felt terrible about themselves due to bullying, and $62 \%$ of all female students believed other students had spread false rumors about them. On average, female students reported more bullying in their school than males. Caucasian students reported the highest rate of cyberbullying. Based on their findings, the authors discussed the issues surrounding bullying in urban schools and gave suggestions regarding approaches that can help students better cope with bullying.
\end{abstract}

Keywords: Bullying, cyberbullying, urban males, middle school.

\section{Introduction}

Bullying affects nearly one-quarter of the students in the United States (Seals \& Young, 2003). The National Education Associate (NEA) and the United States Department of Education believe that nearly a third of all students in the United States have been impacted by bullying (Nishioka et al., 2011). Bullying is an inequality of power or strength demonstrated through regular actions that remind the "weaker" party of their lack of power and strength. An imbalance in the relationship must be present to be considered 
bullying (Olweus, 1993). Relational bullying consists of some actions that focus on excluding others through gossiping and sharing rumors (Williford \& Zinn, 2018). The goal of the bully to push students to dislike another student or group of students. Their actions are often physical, and they use behaviors such as hitting or threatening another student or steal their possessions. Whether physical or relational, bullying is detrimental to students (Bondu, Rothmund \& Gollwitzer, 2016).

\section{Background}

According to Lohmann and Taylor (2009), bullies are aggressive, their actions are deliberate, and their behavior is intentional and forceful. They intend to harm other students by using physical force or intimidation. Technology such as Facebook, Snapchat, and Instagram are tools that a bully will often use for continuous harassment of their victims (Chester et al., 2019). The bully then separates or excludes the student from his or her peer group. Datta, Dewey \& Huang, (2017) found that those students who were bullied by peers demonstrated a more significant amount of withdrawing from school involvement, lower grades, and had a negative perception of the school environment. In their research on teacher's perceptions of bullying, Waters, and Mashburn (2017) noted that $85 \%$ of teachers reported that they had seen bullying among their students. They reported that verbal bullying was the most common form and the most severe. However, Waters and Mashburn (2017) have noted that often, teachers minimize bullying by referring to it as "teasing" or "gossiping." In a research study examining these adolescents, Bondu et al. (2016) found that they experience more frequent and stronger emotions than both younger and older students. Poor emotional understanding and difficulties in regulating negative emotions have been linked to aggression in adolescence, which can then lead to bullying. Anger leads adolescents to misinterpret existing cues, and this misinterpretation might result in physical, verbal, and indirect aggression (Craig et al., 2009). Bullying is very detrimental for adolescents and affects their mental health, social norms, and overall wellbeing (Jose, Ryan \& Pryor, 2012). Academic achievement can suffer, and students who are bullied can begin to replicate the bullying behaviors they receive.

Gender differences are significant when evaluating the relationship between bullying behaviors and adolescents' coping skills strategies. Based on previous research findings (Wang, Iannotti, \& Nansel, 2009), boys were more involved in physical or verbal bullying, whereas girls were more involved in relational bullying. Therefore, a bully might have a more powerful effect on girls due to their heightened concern about social consequences for their behavior. In that way, social exclusion can be seen as a powerful tool for girls to achieve dominance. Hellstrom and Beckman (2019) found that boys use 
bullying as a tool to alleviate aggression and that the most natural target for this aggression was the "weak guy." Boys who display non-normative behavior may be seen as easier targets (Kowalski, Limber \& McCord, 2019). Accordingly, boys and girls tend to have different views about seeking adult help (Hellstrom \& Beckman, 2019). Girls demonstrate more significant helpseeking behaviors generally, whereas boys report more passive, avoidant, and suppressive behaviors (Kowalski et al., 2019). From these findings, girls who report bullying victimization demonstrate more significant psychological consequences, while boys report more adverse physical health outcomes (Kowalski et al., 2019).

Bullying based on race has been found in students at a very young age, and higher risks of bullying pertain to certain racial groups (Larochette, 2009). Students perceive themselves as belonging to the same social category, and then they can compare and distinguish themselves from other groups. Therefore, early racial bias might lead to hostility and prejudice between groups of different racial backgrounds (Larochette, 2009). Behaviors related to racially driven bullying include derogatory and racial slurs, physical attacks, and other methods of exclusion because of racial identity (Lim \& Hoot, 2015). Bullying is highest among Caucasian students, followed by Hispanic and African American students (Lim \& Hoot, 2015). Therefore, the acceptance of diversity in schools is essential, because schools, where diversity is accepted, are much more likely to have lower rates of bullying behavior.

Cyberbullying occurs via electronic communication, and it has been found that $60 \%$ of youths who had experienced cyberbullying also experienced traditional forms of bullying (Chester et al., 2019). Cyberbullying is an aggressive, intentional act using electronic forms of contact, which, repeatedly and over time, prevents students from defending themselves (Kowalski et al., 2019 Because many students who experience cyberbullying also experience traditional bullying, it is challenging to determine significant differences between the two forms of bullying (Kowalski et al., 2019). A 2013 study suggested that $88 \%$ of students who had been cyberbullied had experienced traditional bullying as well.

\section{Research Method}

The study took place in four urban middle schools within a school district in Ohio. Within the 4 four schools, 185 students between 5 th and 8th grades completed a 17-item survey that was distributed electronically through their school email. Questions in the survey were developed from the research of Dan Olweus(1993) and his highly effective bullying prevention program and protocol (Limber,2004). Participants were invited to take part in the survey during guidance units or were invited to participate by their homeroom teacher. The survey was self-administered with an online program that 
allowed researchers instant and continuous access to the data. The selfadministered survey allowed students to answer questions at their own pace and on their own time. Both school laptops and personal phones were used to self administer the test. The survey sought to collect demographic data, student experiences with bullying, their trust in adults to intervene and help with incidences of bullying, and their knowledge and experience with cyberbullying.

\section{Results}

Of the 185 survey responses received, the results compared student perception data regarding individual popularity, the popularity of others, rumors, cyberbullying, and if students were affected emotionally. In all, 31\% of the total respondents felt terrible about themselves due to other students bothering them. Of these students, $72 \%$ were female, showing a much higher proportion of female students who feel affected by others than females in the general population of the survey. Approximately $40 \%$ of those same students indicated that they also experienced cyberbullying, almost twice the $21 \%$ of general responses to the survey.

Table 1:

Prevalence of student perceptions on popularity and bullying behaviors

\begin{tabular}{|c|c|c|c|c|c|c|c|}
\hline & $\begin{array}{l}\text { Number } \\
\text { of } \\
\text { responde } \\
\text { nts }\end{array}$ & $\begin{array}{l}\text { \% who } \\
\text { complet } \\
\text { ed the } \\
\text { survey }\end{array}$ & $\begin{array}{l}\text { Do } \\
\text { you } \\
\text { think } \\
\text { you } \\
\text { are } \\
\text { popul } \\
\text { ar in } \\
\text { schoo } \\
1 ?\end{array}$ & $\begin{array}{l}\text { Do you } \\
\text { think } \\
\text { others } \\
\text { are } \\
\text { stronge } \\
\mathrm{r} \text { or } \\
\text { more } \\
\text { popula } \\
\text { r? }\end{array}$ & $\begin{array}{l}\text { Have } \\
\text { student } \\
\mathrm{s} \text { ever } \\
\text { spread } \\
\text { rumors } \\
\text { about } \\
\text { you on } \\
\text { purpos } \\
\mathrm{e} ?\end{array}$ & $\begin{array}{l}\text { Have } \\
\text { student } \\
\text { s } \\
\text { bothere } \\
\text { d you } \\
\text { enough } \\
\text { that } \\
\text { you } \\
\text { feel bad } \\
\text { about } \\
\text { yoursel } \\
\text { f? }\end{array}$ & $\begin{array}{l}\text { Have you } \\
\text { ever been } \\
\text { cyberbullie } \\
\text { d? }\end{array}$ \\
\hline Total & 185 & & 93 & 111 & 102 & 58 & 39 \\
\hline \multicolumn{8}{|l|}{ Grade } \\
\hline $5^{\text {th }}$ & 10 & 5 & .8 & .5 & .6 & .1 & 0 \\
\hline $6^{\text {th }}$ & 27 & 15 & .48 & .67 & .48 & .44 & .30 \\
\hline $7^{\text {th }}$ & 89 & 48 & .56 & .60 & .55 & .25 & .24 \\
\hline $8^{\text {th }}$ & 59 & 32 & .37 & .58 & .58 & .36 & .17 \\
\hline \multicolumn{8}{|l|}{ Gender } \\
\hline Female & 107 & 58 & .39 & .52 & .63 & .39 & .24 \\
\hline Male & 78 & 42 & .65 & .70 & .45 & .21 & .15 \\
\hline \multicolumn{8}{|l|}{ Ethnicity } \\
\hline $\begin{array}{l}\text { African } \\
\text { American }\end{array}$ & 68 & 37 & .53 & .62 & .60 & .25 & .16 \\
\hline Hispanic & 24 & 13 & .38 & .63 & .46 & .38 & .17 \\
\hline
\end{tabular}




\begin{tabular}{|l|l|l|l|l|l|l|l|}
\hline Caucasian & 15 & 8 & .33 & .87 & .47 & .47 & .33 \\
\hline Multiracial & 33 & 18 & .58 & .61 & .42 & .21 & .18 \\
\hline $\begin{array}{l}\text { Asian/Nati } \\
\text { ve } \\
\text { American }\end{array}$ & 5 & 1 & & & & & \\
\hline $\begin{array}{l}\text { No } \\
\text { response }\end{array}$ & 40 & 22 & & & & & \\
\hline Total & 185 & & 93 & 111 & 102 & 58 & 39 \\
\hline
\end{tabular}

\section{Grade Level}

Fifth-grade students comprised $5 \%$ of the survey responses, sixthgrade students contributed $15 \%$, seventh-grade students were $48 \%$, and eighth-grader students added $32 \%$ of completed surveys. The perception of traditional bullying behaviors appears to be evenly distributed among the grades polled with a standard deviation of $.056(\mathrm{CV}=.097)$ between student responses. Sixth-grade students responded with the highest frequency that they were affected by bullying behaviors. In contrast, only one fifth-grade student reported feeling poorly due to others bothering him or her. Reported rates for cyberbullying were highest among the sixth-grade respondents. No fifth-grade students reported experiencing cyberbullying.

\section{Gender}

It was found that $58 \%$ of responses were from female students, while the remaining $42 \%$ of respondents identified as male. Consistent with other studies on bullying, female students reported higher rates of traditional bullying behaviors and cyberbullying than male students. Females reported traditional bullying behaviors, an average of $18 \%$ more frequently than male students. Rates for cyberbullying were more comparable between the genders, but there were nearly $8 \%$ more female reports than males. Males reported higher rates of perceived popularity and a significantly higher number of responses regarding the feeling that others were more popular or stronger.

\section{Ethnicity}

The following ethnicities were reported: African American (37\%), Caucasian (8\%), Hispanic (13\%), and Multiracial (18\%). Nearly $22 \%$ of respondents did not include ethnicity information, which did not meet our criteria; as such, the responses were not included in the results. Asian American and Native American responses were collected at a rate of $1 \%$ each. Due to such a small sample size, these responses were excluded as well.

\section{Discussion}

The results of this study found a significant difference between grade levels who have reported being affected by bullying behaviors. The $6^{\text {th }}$-grade 
students reported with the highest frequency that they were affected by bullying behaviors, which could be attributed to the school climate. Another contributing factor may be the lack of teacher support and school safety presented within the school climate. For adolescents, the school climate offers one of the most critical social contexts for mental and behavioral wellness, including self-esteem, interpersonal relationships, and coping strategies (Cross et al., 2018). When teachers form positive bonds with students, classrooms become supportive spaces in which students can engage in academically and socially productive behaviors (Hughes, Cavell \& Wilson, 2001).

Further research would need to be conducted to assess the direct effects of classroom management and teacher-student relationships as contributing factors to bullying behaviors. No fifth-grade students reported experiencing cyberbullying. This could be attributed to a lack of understanding of cyberbullying, less frequent use of technology, or increased parental monitoring of technology. Access to technology and parental monitoring were not assessed during this survey, so it would be difficult to determine the reason for the lack of cyberbullying reports for this age group.

The results of this study also showed significant results regarding gender and the effects of bullying and cyberbullying. Female students reported higher rates of traditional bullying behaviors and cyberbullying than male students; whereas, males students reported higher rates of perceived popularity and a significantly higher number of responses regarding feeling that others were more popular or stronger. These findings match closely with previous research, stating that female students are more often victimized by bullying than male students (Craig et al., 2009). At the same time, female students put particular emphasis on positive social relationships, whereas male students have a stronger focus on aspects of power. It appears that the most critical risk factor for bullying by students is the lack of empathy because students who are less engaged with others are at more risk of being bullied. Our study also reported that $40 \%$ of female students had experienced cyberbullying. These findings are supported by the research that indicates that female students' online friendships are more frequent than male students. Female students use social media to post personal images, share stories, experiences, seek advice on private matters and appearance, and plan and organize social activities (Chibbaro, 2007). Female students are at higher risk for problems associated with bullying, such as gossip, name-calling, spreading rumors, coercion, and shaming (Chibbaro, 2007).

Significantly fewer Hispanic and Caucasian students reported feeling popular at school. Caucasian students reported perceiving their African American, Multiracial, or Hispanic students as more popular and stronger. African American students reported that rumors were spread about them, 
while Caucasian students were negatively affected by bullying behaviors but were cyberbullied more than the students of other ethnicities.

\section{Conclusion}

\section{Whole-School Interventions}

Whole-school approaches consist of social-emotional learning or character education. Instruction helps students relate to each other with empathy. These programs focus on character traits such as respect, honesty, trust, and responsibility (Cross et al., 2018). Many whole-school approaches use mentors with urban youth who often lack strong role models (Jose et al., 2012). Mentors have been shown to improve the school climate and student achievement. These mentors help students to see the possibility of job opportunities that may not be present within their neighborhoods (Zimmerman, Bingenheimer \& Notaro, 2002).

\section{Individual Interventions}

Individual approaches focus on providing positive role models to help students develop specific goals and a purpose. Interventions by school counselors and psychologists have proven to be very successful with students. Cognitive Behavioral Therapy (CBT) has been proven to be one of the most effective approaches to addressing bullying behavior (Lohmann \& Taylor, 2009). This approach focuses on helping students understand their thoughts, feelings, and actions. CBT can help students who are bullied and have developed maladaptive behaviors by focusing on more positive attributes. CBT focuses on improving low self-esteem and changes negative self-talk that students often have about themselves when they are bullied. CBT can also be used to change the behaviors of the bullies. Often anger is at the core of bullying behaviors as well as the need for power and control. Ironically, many bullies are depressed and come from homes with aggressive parents or adults who bully, CBT has been found helpful in addressing many of these behaviors and the underlying reason that children often bully (Schmidt, Pierce \& Stoddard, 2016).

\section{Cyberbullying Interventions}

Cyberbullying has shown dramatic increases in recent years with social platforms such as Facebook, Snapchat, and Instagram. Schools are beginning to develop programs, and classroom units have been developed to focus on the social and legal aspects of using these platforms in negative ways and as an instrument for cyberbullying (Chibbaro, 2007). These classroom units help adolescents to negotiate online communications. Strategies for sharing private information with other students, such as using language and symbols with less obvious meaning, is a good starting point. Helping students 
establish student-friendly reporting schemes is urgent, and providing self-help resources designed by students, such as informational websites, safety checklists, and social media apps, is critical (Chibbaro, 2007).

\section{Multicultural Interventions}

The urban public schools have become more culturally and ethnically diverse. Students need skills that express an increased understanding of an expanding and diverse population. Teaching about various cultures at an early age will help students understand biases that have already formed about other cultures (Sarraj et al., 2015). Multicultural programs have a positive effect on students, and a knowledge of a diverse population will bring about familiarity and respect. Specific cultural differences should be taught as they pertain to all students, and not as a proof of difference and rejection (Sarraj et al., 2015).

\section{References:}

1. Bondü, R., Rothmund, T., \& Gollwitzer, M. (2016). Mutual long-term effects of school bullying, victimization, and justice sensitivity in adolescents. Journal of Adolescence, 48, 62-72. https://doi.org/10.1016/j.adolescence.2016.01.007eferences

2. Chester, K. L., Magnusson, J., Klemera, E., Spencer, N., \& Brooks, F. (2019). The mitigating role of ecological health assets in adolescent cyberbullying victimization. Youth \& Society, 51(3), 291-317. doi:10:1177/0044118X16673281

3. Chibbaro, J. S. (2007). School counselors and the cyberbully: Interventions and implications. Professional School Counseling, 11(1), 65-68. https://doi.org/10.5330/PSC.n.2010-11.65

4. Craig, W., Harel-Fisch, Y., Fogel-Grinvald, H., Dostaler, S., Hetland, J., \&, HBSC Bullying Writing Group. (2009). A cross-national profile of bullying and victimization among adolescents in 40 countries. International Journal of Public Health, 54, $216 \mathrm{e} 224$. http://dx.doi.org/10.1007/s00038-009-5413-9.

5. Cross, D., Shaw, T., Epstein, M., Pearce, N., Barnes, A., Burns, S., ... Runions, K. (2018). Impact of the Friendly Schools whole-school intervention on transition to secondary school and adolescent bullying behaviour. European Journal of Education, 53(4), 495-513. https://doi.org/10.1111/ejed.12307

6. Datta, P., Dewey, C., \& Huang, F., (2017) The toxicity of bullying by teachers and other school staff. School Psychology Review: December 2017, 46(4), 335-348.

7. Hellström, L. \& Beckman, L. ( 2019). Adolescents' perception of gender differences in bullying. Scandinavian Journal of Psychology. 35(4), 301-312. 
8. Hughes, J., Cavell, T., \& Wilson, V. (2001). Further support for the developmental significance of the quality of the teacher-student relationship. Journal of School Psychology, 39(4), 289-301.

9. Jose, P., Ryan, N., \& Pryor, J. (2012). Does social connectedness promote a greater sense of well-being in adolescence over time? Journal of Research on Adolescence, 22(2), 235251.doi:10.1111/j.1532-7795.2012.00783.

10. Kowalski, R., Limber, S., \& McCord, A. (2019). A developmental approach to cyberbullying: Prevalence and protective factors. Aggression and Violent Behavior, 45, 20-32. Retrieved from https://doi.org/10.1016/j.avb.2018.02.009

11. Larochette, A. (2009). The influences of race, immigrant status, and school climate on the incidence of bullying in Canadian children and adolescents. Anne-Claire Larochette, 2009, 1-88.

12. Lim, S., \& Hoot, J. (2015). Bullying in an increasingly diverse school population: A socio-ecological model analysis. School Psychology International, 36(3), 268-282.

13. Limber, S. (2004b). Implementation of the Olweus Bullying Prevention Program: Lessons learned from the field. In D. Espelage \& S. Swearer (Eds.) Bullying in American Schools: A Social-Ecological Perspective on Prevention and Intervention. (351-363). Mahwah, NJ: Lawrence Erlbaum.

14. Lohmann, C., \& Taylor, J.(2009) The Anger Workbook.Seattle, Wa. Instant Help

15. Nishioka, V., Coe, M., Burke, A., Hanita, M., \& Sprague, J. (2011). Student-reported overt and relational aggression and victimization in grades 3-8. Issues and Answers Report, REL 2011(114), 1-42.

16. Olweus, D. (1993). Bullying at School. Malden, MA: Blackwell Publishing.

17. Sarraj, H., Bene, K., Li, J., \& Burley, H. (2015). Raising cultural awareness of fifth-grade students through multicultural education. Multicultural Education, 22, 39-45.

18. Schmidt, C., Pierce, J., \& Stoddard, S. (2016). The mediating effect of future expectations on the relationship between neighborhood context and adolescent bullying perpetration. Journal of Community Psychology, 44(2), 232-248. https://doi.org/10.1002/jcop.21761

19. Seals, D., \& Young, J. (2003). Bullying and victimization: Prevalence and relationship to gender, grade level, ethnicity, self-esteem, and depression. Adolescence. 38(152), 735-746.

20. Wang, J., Iannotti, R.,\& Nansel, T. (2009). School bullying among adolescents in the United States: Physical, verbal, relational, cyber. Journal of Adolescent Health, 45 (4), 368-375. 
21. Waters, S., \& Mashburn, N. (2017). An investigation of middle school teachers' perceptions on bullying. Journal of Social Studies Education Research, 8(1), 1-34.

22. Williford, A., \& Zinn, A. (2018). Classroom-level differences in childlevel bullying experiences: implications for prevention and intervention in school settings. Journal of the Society for Social Work and Research, 9(1), 23-48.

23. Zimmerman, M. A., Bingenheimer, J. B., \& Notaro, P. C. (2002). Natural mentors and adolescent resiliency: A study with urban youth. American Journal of Community Psychology, 30(2), 221-243. 